\section{Foreign direct investment and institutional stability: who drives whom?}

\section{Foreign direct investment}

Nihal Mahmood

International Centre for Education in Islamic Finance, Kuala Lumpur, Malaysia

Mohammad Hassan Shakil

Taylor's University, Subang Jaya, Malaysia

Ishaq Mustapha Akinlaso

International Centre for Education in Islamic Finance,

Kuala Lumpur, Malaysia, and

Mashiyat Tasnia

International Islamic University Malaysia, Kuala Lumpur, Malaysia
Received 15 May 2018 Revised 21 October 2018 Accepted 22 October 2018

\begin{abstract}
Purpose - The purpose of this paper is to examine the relationship between foreign direct investment (FDI) flows and institutional stability. The focus country is Canada. It is one of the few countries where the economy remained relatively stable compared to other economies during the Global Financial Crisis. It is crucial for Canada to determine the optimal level of institutional development to attract more FDI and sustain the sound financial stability in future.
\end{abstract}

Design/methodology/approach - This study uses the auto-regressive distributive lag (ARDL) approach to understand the relationship between FDI and institutional stability along with other controlled variables, for instance, gross national product, inflation and exports.

Findings - The key finding of this work is that FDI and institutional stability are cointegrated in the long run. The error correction model of ARDL shed light on institutional stability being an exogenous variable, and FDI is an endogenous variable. Institutional stability affects FDI, as it is exogenous. The findings will help policymakers to implement policies to strengthen the institution's settings, and this, in turn, will attract more investment.

Originality/value - Based on previous theoretical and empirical literature, most of the research points to FDI positively affect institutional stability. In some cases, the relationship does not always hold true. This study will fix the gap in the literature by investigating the relationship between FDI and institutional stability of Canada.

Keywords FDI, Foreign direct investment, ARDL, Economic growth, Institutional stability

Paper type Research paper

(C) Nihal Mahmood, Mohammad Hassan Shakil, Ishaq Mustapha Akinlaso and Mashiyat Tasnia. Published in Journal of Economics, Finance and Administrative Science. Published by Emerald Publishing Limited. This article is published under the Creative Commons Attribution (CC BY 4.0) licence. Anyone may reproduce, distribute, translate and create derivative works of this article (for both commercial and non-commercial purposes), subject to full attribution to the original publication and authors. The full terms of this licence may be seen at http://creativecommons.org/licenses/by/4.0/ legalcode

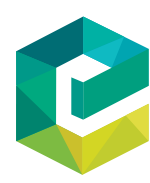

Journal of Economics, Finance and Administrative Science Vol. 24 No. 47, 2019 pp. $145-156$ pp. 145-156
Emerald Publishing Limited 2077-1886 DOI 10.1108/JEFAS-05-2018-0048 
JEFAS

24,47

\section{Introduction}

Foreign direct investment (FDI) inflows were $\$ 1.45 \mathrm{tn}$ in 2013 and are expected to rise about 5 per cent in 2017 to almost $\$ 1.85 \mathrm{bn}$ (United Nations Conference on Trade and Development [UNCTAD], 2017). The top host countries for FDI inflows as of 2016 include the USA, Ireland, Hong Kong, China and Singapore. Also, North America is the top region of FDI outflow. To further add, from the period of 2000 to 2012, about 55 countries adopted 1,082 institutional policy changes, with the goal of creating a more favourable environment for foreign investors (Demir, 2016).

Prior studies indicate that proper institutions encourage private investments, improve the efficiency of the economic system and encourage economic growth (Acemoglu et al., 2005; Ahmad and Ahmed, 2014; Hall and Jones, 1999; Rodrik et al., 2004). Institutions play a crucial role in disciplining the behaviour of economic agents, thus encouraging setting rules and limit opportunism and build transactional trust in financial transactions, and ultimately enhance the confidence of foreign investor and FDI inflows (Ahmad and Ahmed, 2014). In a study by Makki and Somwaru (2004), the results pointed to FDI and exports positively impacting economic growth. The study looked at 66 developing countries from 1970 to 2000. Wang and Meng (2004) found that it is more critical to higher-income countries, whereas international trade is more critical for lower-income countries (Tekin, 2012).

On the other hand, other studies were not able to find a direct link between FDI and institutional development (Buchanan et al., 2012; Wheeler and Mody, 1992). In another study by Harms and Ursprung (2002), political and civil liberties were found to be factors that attracted FDI as opposed to institutional aspects (Ahmad and Ahmed, 2014). As such, it is inconclusive as to if institutional stability plays a fundamental role in encouraging FDI.

Furthermore, there is theoretical literature that suggesting FDI can adversely impact economic growth. It is because the growth accelerating the effect of FDI is based on the assumption that this does not crowd out domestic investment (Tekin, 2012). There is also theoretical literature that supports the notion of institutional stability encouraging FDI. For instance, the Douglas North approach discusses how institutions play a crucial role in economic growth. Even from a theoretical perspective, it seems that the literature is inconclusive on the exact role that institutional stability plays, and how other factors react to it.

This paper will focus on Canada, because in recent years it is one of the economies that have performed exceptionally well, despite the global financial crisis in the past decade. Despite its proximity to the USA economy, none of the banks in Canada failed. Unlike other central banks, the Bank of Canada did not resort to quantitative easing during this time. It can be attributed to proper regulation, and the willingness of business and the government to react decisively. As Freeland (2010) quoted in the Financial Times in 2010, "One of the most important policy debates today is what caused the crisis and what should be done to prevent repetition that's where Canada comes in. It is a real-world, real-time example of a banking system in a medium-sized, advanced capitalist economy that worked. Understanding why the Canadian system survived could be a key to making the rest of the world equally robust". While this paper will not provide the answer to avoiding a future crisis, it will provide some insight that can benefit policymakers around the world.

The primary objective of this paper is to explore the long run impact of institutional quality on FDI concerning the Canadian economy by applying the auto-regressive distributed lag (ARDL) cointegration approach. FDI is a critical part of economic growth and knowing what drives this is necessary for policymakers to adopt strategies to ensure the correct balance of FDI that should maintain. While the focus variables in this study are FDI and institutional stability, other macroeconomic variables were also included in the 
model, namely, gross national product (GNP), inflation and exports. These variables were chosen based on similar studies that have been conducted by other authors (Ahmad and Ahmed, 2014; Asif and Majid, 2017; Aziz, 2017; Kurul, 2017).

The key findings of this paper are that the variables are cointegrated, indicating that there is a long run theoretical relationship between them. The error correction model (ECM) shed light on institutional stability being an exogenous variable, and FDI is an endogenous variable. As such, for policymakers to attract more FDI into Canada, they must focus on the stability level of institutions, which will, in turn, attract FDI.

The paper is divided into a total of five sections. Section 2 in this paper discusses the literature review, which reviews both theoretical and empirical controversies on the issue. Sections 3 and 4 explain the methodology and empirical results and the discussion. Finally, Section 5 concludes providing recommendations for policymakers.

\section{Literature review}

Institutional quality is crucial to attract FDI (Kurul, 2017). Good governance of a country, for instance, political stability, regulatory quality and control of corruption are the prerequisite for attracting FDI inflow (Kaufmann et al., 2011). Weak institutional quality is an obstacle for FDI (Aziz, 2017). The literature from previous studies shows that there is a link between institutional quality and FDI (Ahmad and Ahmed, 2014; Asif and Majid, 2017; Aziz, 2017). Some studies found a positive relationship between institutional quality and FDI (Aziz, 2017; Buchanan et al., 2012; Kurul, 2017). Aziz (2017) investigated the influence of institutional quality on FDI by considering Arab countries between 1984 and 2012 and found a substantial positive association between them. Kurul (2017) examines the effect of institutional quality on FDI by using panel threshold methodology and considers the developing countries. The author finds a positive relationship between institutional quality and FDI after attaining a certain threshold level of institutional quality. Besides, Buchanan et al. (2012) studied the impact of institutional quality on FDI between developed and emerging countries and found a positive association between them. However, poor institutional quality, which includes factors such as corruption, bureaucratic delays and weak law and order governance; adversely impact FDI in developing countries (Ahmad and Ahmed, 2014). According to Globerman and Shapiro (1999), better institutional quality encourages FDI inflows, as it makes it easier for multinational corporations to invest abroad. Corruption was found to be the most significant deterrent to FDI, according to a study done by Brunetti and Weder (1998).

On the other hand, not all studies show that there is a strong link between FDI and institutional stability. In a study conducted by Wheeler and Mody (1992), they were not able to find any relationship between the two. It is possible that institutional stability has an indirect impact on FDI since it affects factors such as human capital and quality of public facilities, which affect FDI. A study by Jun and Singh (1996) concluded that institutions do not have a substantial impact in promoting FDI. Besides, the Douglas North approach discusses the role of institutions in economic growth and investment (Faundez, 2016). According to North, institutions affect economic growth by increasing or decreasing transaction and production costs. When institutions are inefficient or unstable, that contributes to higher production costs (Ahmad and Ahmed, 2014).

Further, Dunning's eclectic paradigm examines why local firms choose to operate beyond the domestic economy (Stoian and Filippaios, 2008). There are three critical reasons for this, consisting of ownership advantage, internalisation advantage, and locational advantage. Based on Douglas North and Dunning's theoretical underpinnings, there seems to be a relationship between FDI and institutional stability (Faundez, 2016; Stoian and
Foreign direct investment 
JEFAS

24,47

148

Filippaios, 2008). However, there is also the concern of crowding out domestic investment (Tekin, 2012). As such, it is not just institutions that affect FDI, but also ensuring there is a healthy balance of domestic and international investments. Further, Bevan and Estrin (2004) found that labour cost, market size and complexity are significant determining factors for FDI inflows into European transitions economies.

Developed countries are known to push for more conditionality requirements when it comes to dealing with foreign governments concerning trade policies, transparency, law, and the business environment (Ahmad and Ahmed, 2014). An example of this is the 1977 US Foreign Corrupt Practices Act, banning the US firms from bribing foreign governments, even if that law does not exist abroad, for instance, in India or China. Such legislation does encourage developing countries to adopt the standards of developed nations (Demir, 2016). Some studies suggest that institutional development is one of the sources of competitive advantage affecting the long-run growth of a country (Demir, 2016).

Most of the previous studies consider cross-country analysis of institutional stability and FDI (Aziz, 2017; Demir, 2016; Kurul, 2017). In the cross-country regression, it is assumed that the data are homogeneous, which is a restrictive assumption. Besides, institutional aspects differ country to country because of the difference in regulation, geography and other political aspects and the results for cross country study could be misleading (Ahmad and Ahmed, 2014; Deaton, 1989). The paper will contribute to the literature by investigating the relationship between institutional stability and FDI and incorporating ARDL cointegration approach. Previous studies focus on the linear relationship between FDI and other factors, for instance, infrastructure, financial development and so on. To be the best of our knowledge, there are no studies that investigate the impact of institutional stability on FDI by considering the case of Canada. The ARDL is the appropriate approach to find out the suitable level of institutional stability which leads to a positive or negative effect on FDI and help regulators and policymakers to decide the optimal level for institutional stability which will lead to maximising FDI growth. The paper has undertaken a humble attempt to investigate the understudied area and help the policymakers to take a strategic decision on institutional stability and attract more FDI in the economy.

\section{Data and methodology}

This paper aims to analyse the relationship between institutional quality and FDI. However, simple bivariate studies suffer omission bias (Appiah, 2018; Caporale and Pittis, 1995). Hence other variables were included in our model to reduce omission bias and better reflect causality. The study employed annual time series data spanning the period from 1981 to 2014, consisting of a total of 33 observations. The model comprised of institutional quality variable (institutional stability) obtained from International Country Risk Guide database and inflation, GNP, exports and FDI derived from World Bank's World Development Indicators (WDI).

The functional form of the model is as follows [equation (1)]:

$$
I N S T=f(I N F, G N P, X P, F D I)
$$

Where:

$$
\begin{aligned}
I N S T & =\text { institutional stability; } \\
I N F & =\text { inflation; } \\
G N P & =\text { gross national product; } \\
X P & =\text { exports; and } \\
F D I & =\text { foreign direct investment. }
\end{aligned}
$$


This study used the "ARDL co-integration approach to testing the existence of a long-term relationship with the lagged levels of the variables. It helps to identify the dependent variables (endogenous) and the independent variables (exogenous). More so, if the relationship between the variables is long term, then the ARDL analysis creates the ECM equation for every variable, which provides information through the estimated coefficient of the error-correction term about the speed at which the dependent variable returns to equilibrium once it is shocked" (Shakil et al., 2018 p. 65). The ARDL model specifications of the functional relationship between institutional stability (INST), inflation (INF), gross national product (GNP), exports (XP) and foreign direct investment (FDI) can be estimated in equation (2):

$$
\begin{aligned}
\operatorname{DINST}_{t}= & \alpha_{0}+\sum_{i=1}^{k} b_{1} \operatorname{DINST}_{t-i}+\sum_{i=0}^{k} b_{2} \text { IINF }_{t-i}+\sum_{i=0}^{k} b_{3} D G N P_{t-i}+\sum_{i=0}^{k} b_{4} D X P_{t-i} \\
& +\sum_{i=0}^{k} b_{5} D \text { DDI }_{t-i}+\delta_{1} \text { LINST }_{t-1}+\delta_{2} \text { LINF }_{t-1}+\delta_{3} L G N P_{t-1}+\delta_{4} L X P_{t-1} \\
& +\delta_{5}{ }_{L F D I_{t-1}}+u_{t}
\end{aligned}
$$

Where:

$\mathrm{k}=\mathrm{Lag}$ order

The null hypothesis of the non-existence of a long-run relationship which is denoted by $F_{\text {LINST }}($ LINST $\mid L I N S T$, LINF , LGNP, LXP , LFDI) and the other components of Equation (2) are denoted as follows:

$$
\begin{gathered}
F_{\text {LINF }}(|\mathrm{LINF}| \text { LINST, LGNP }, \text { LXP }, \text { LFDI }), \\
F_{L} G N P(|L G N P| L I N F, \text { LINST }, L X P, L F D I), \\
F_{L X P}(|L X P| L G N P, L I N F, \text { LINST }, \text { LFDI }), \\
F_{L F D I}(|L F D I| L X P, L G N P, L I N F, \text { LINST })
\end{gathered}
$$

These are tested against the alternative hypothesis of the existence of co-integration.

$$
H_{o}=\delta_{1}=\delta_{2}=\delta_{3}=\delta_{4}=\delta_{5}=0
$$

Against:

$$
H_{1}=\delta_{1} \neq \delta_{2} \neq \delta_{3} \neq \delta_{4} \neq \delta_{5} \neq 0
$$

The calculated $F$-statistics derived from Wald test are compared with Pesaran et al. (2001) critical values. If the calculated $F$-statistics falls below the lower bound critical values, then the study will fail to reject the null hypothesis of the non-existence of a long-run relationship. Moreover, if the calculated $F$-statistics lies between the lower bound and Upper bound of the critical values, then the result is inconclusive. On the other hand, if the calculated $F$-statistics 
JEFAS

24,47

150

is higher than the Upper bound critical values, then the paper will reject the null hypothesis non-existence of a long-run relationship.

Once valuing the existence of long-run relationship between variables the next step is to select the optimal lag length by using standard criteria such as Swartz Bayesian (SBC) or Akaike Information (AIC). Only after the test, long run and short run coefficients could be predicted. ARDL long-run form is exhibited in equation (3):

$$
\begin{aligned}
\operatorname{LINST}_{t}= & \alpha_{0}+\sum_{i=1}^{k} b_{1} \operatorname{LINST}_{t-i}+\sum_{i=0}^{k} b_{2} L_{I N F_{t-i}}+\sum_{i=0}^{k} b_{3} L G N P_{t-i}+\sum_{i=0}^{k} b_{4} L X P_{t-i} \\
& +\sum_{i=0}^{k} b_{5} L F D I_{t-i}+u_{t}
\end{aligned}
$$

The error correction term which was used in the ARDL short-run model to depict the short run dynamics is shown in equation (4):

$$
\begin{aligned}
\operatorname{DINST}_{t}= & \alpha_{0}+\sum_{i=1}^{k} b_{1} \text { DINST }_{t-i}+\sum_{i=0}^{k} b_{2} D_{I N F_{t-i}}+\sum_{i=0}^{k} b_{3} D G N P_{t-i}+\sum_{i=0}^{k} b_{4} D X P_{t-i} \\
& +\sum_{i=0}^{k} b_{5} D F D I_{t-i}+b_{6} E C T_{t-1}
\end{aligned}
$$

Where:

$E C T$ = lagged error-correction term.

The paper will test the null hypothesis $\left(H_{O}\right)$ of the "non-existence of the long-run relationship" against the alternative of "the existence of the long-run relationship".

$$
\begin{aligned}
& H_{0}=b_{1}=b_{2}=b_{3}=b_{4}=b_{5}=0 \\
& H_{1}=b_{1} \neq b_{2} \neq b_{3} \neq b_{4} \neq b_{5} \neq 0
\end{aligned}
$$

Logarithmic transformations of all variables were calculated to achieve stationarity in variance. After that, the study will begin empirical testing by determining the stationarity of all variables in consideration. Proceeding with the testing of the cointegration later is necessary. "Ideally, the variables should be I(1), in that they only become stationary after their first difference. The differenced form for each variable used is created by taking the

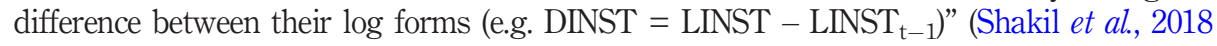
p. 67).

\section{Findings and interpretations}

The Augmented Dicky-Fuller (ADF) test was conducted to see if there were any unit roots and to identify the order of integration for each variable. Further tests were done using Phillips-Perron (PP), which is different from ADF since it deals with autocorrelation and heteroscedasticity in the errors. As such it is a more comprehensive test. Since the variables 
in this study are a combination of stationary and non-stationary variables. The ARDL approach is used. This technique can be applied regardless of the order of integration. Also, it is more robust when dealing with smaller sample sizes and when there is cointegration.

The variables are tested for cointegration based on the F-statistic. The null hypothesis is that there is no cointegration. The F-statistic is compared against two bounds of critical values. Based on the bound test, cointegration exists if the F-statistic is above the upper limit. Further, ECMs was drawn from ARDL. From this, the outcome of long-run estimates can be determined. The testing will begin with diagnostic tests. After this, the stationarity of the variables will be determined. Ideally, in level form, the variables should be nonstationary, and in the differenced form they should be stationary. It was not found to be the case for this study, so the ARDL approach was applied.

To check the unit roots of the variables, ADF and Phillip-Peron (PP) test was conducted. The results of these tests can be used to determine whether ARDL modelling needs to be applied. The variables were found to be a combination of stationary and non-stationary, and the results were not consistent in either of the tests. As such, ARDL modelling was applied (Tables I and II).

Next, the vector autoregression (VAR) must be determined, to determine the VAR order for the ARDL model. As a side note, this is not necessary given that ARDL finds the appropriate lag for each variable. As per Table III, there is a conflict in the results. AIC suggests four lags, whereas SBC suggests one lag.

To address this conflict, each variable was checked to see if there was any autocorrelation. The test indicated that there is, as such a VAR order two was selected, which is in between AIC and SBC.

Table IV shows that the F statistics for DINF and DXP are 34.46 and 5.57, respectively, at the 5 per cent significance level. Since there are two variables above the upper bound, the null hypothesis can be rejected (the null hypothesis is that there is no cointegrating long-run relationship). The results indicate that institutional stability (DINST), inflation (DINF), foreign direct investment (DFDI), gross national product (DGNP) and exports (DXP) move together in the long run. As such, there is a theoretical relationship between the variables. To better understand what happens when the results deviate in the short-run, and how long it takes for it to return to long-run equilibrium, the ECM is applied as shown in Table V.

\begin{tabular}{lccl}
\hline Variables & Test statistic & Critical value & Implication \\
\hline Level form & & & \\
LINST & -2.5143 & -3.6316 & Non-stationary \\
LINF & -4.4857 & -3.6316 & Stationary \\
LFDI & -3.2683 & -3.6278 & Non-stationary \\
LGNP & -2.6748 & -3.6316 & Non-stationary \\
LXP & -0.97975 & -3.6278 & Non-stationary \\
Differenced form & & & \\
DINST & -3.6755 & -2.9447 & Stationary \\
DINF & -3.6614 & -2.9681 & Stationary \\
DFDI & -3.9962 & -2.9753 & Stationary \\
DGNP & -4.5725 & -2.9447 & Stationary \\
DXP & -4.2765 & -2.9447 & Stationary
\end{tabular}

Source: Own elaboration
Foreign direct
investment

151 


\begin{tabular}{llccc} 
JEFAS & Variables & Test statistic & Critical value & Implication \\
\cline { 2 - 5 } 24,47 & Level form & & & \\
& LINST & -1.3765 & -3.6494 & Non-stationary \\
& LINF & -1.5047 & -3.6494 & Non-stationary \\
& LFDI & -3.6531 & -3.6494 & Stationary \\
$\mathbf{1 5 2}$ & LGNP & -2.4345 & -3.6494 & Non-stationary \\
& LXP & -1.2803 & -3.6494 & Non-stationary \\
& Differenced form & & & Stationary \\
& DINST & -4.3384 & -2.927 & Stationary \\
& DINF & -6.4501 & -2.927 & Stationary \\
& DFDI & -10.9645 & -2.927 & Stationary \\
Table II. & DGNP & -6.6588 & -2.927 & Stationary \\
PP test & DXP & -4.647 & -2.927 & \\
\hline
\end{tabular}

Table III.

\begin{tabular}{lccr}
\hline & AIC & Criteria & SBC \\
\hline Optimal order & 4 & 1 \\
Source: Own elaboration & & \\
\hline
\end{tabular}

VAR order selection Source: Own elaboration

\begin{tabular}{lccc}
\hline Variables & $F$-statistic & Critical value lower & Critical value higher \\
\hline DINST & 1.613 & 3.189 & 4.239 \\
DINF & $34.4583^{*}$ & 3.189 & 4.239 \\
DFDI & 4.0189 & 3.189 & 4.239 \\
DGNP & 1.2883 & 3.189 & 4.239 \\
DXP & $5.5737^{*}$ & 3.189 & 4.239
\end{tabular}

F-statistics for testing the existence of a long-run relationship

Notes: The critical values are taken from Pesaran et al. (2001), unrestricted intercept and no trend with four regressors; * denotes rejecting the null at the $5 \%$ level

Source: Own elaboration

Table V.

\begin{tabular}{lcccc}
\hline Variables & Coefficient & Standard error & T-statistics & $p$-value \\
\hline ECM (-1) DINST & -0.36306 & 0.24451 & -1.4849 & 0.161 \\
ECM (-1) DINF & 0.020907 & 0.09132 & 0.22894 & 0.822 \\
ECM (-1) DFDI & -1.1075 & 0.19241 & -5.7558 & 0 \\
ECM (-1) DGNP & 0.45081 & 0.098565 & 4.5737 & 0 \\
ECM (-1) DXP & -0.59946 & 0.11768 & -5.0941 & 0
\end{tabular}

ECM of ARDL Source: Own elaboration 
The t-statistic or $p$-value of the error correction coefficient, tells us if deviating from the equilibrium significantly affects the dependent variable, which allows us to classify the variable as exogenous (leader) or endogenous (follower). Also, the size of the coefficient tells us the speed of short-run adjustment in converging back to equilibrium.

From the table above, there are two exogenous variables and three endogenous variables. Institutional stability (DINST) and inflation (DINF) are independent variables, given that the $p$-value is more significant than 5 per cent. Foreign direct investment (DFDI), gross national product (DGP), and exports (DXP) were all found to be dependent variables. The result of the exogenous variables does not contradict the literature. From past studies, we know that institutional stability does impact FDI, and they tend to move in the same direction (as in higher institutional stability attracts higher FDI). The results are consistent with the study of Kurul (2017), Ahmad and Ahmed (2014) and (Aziz, 2017). They found a significant relationship between institutional quality and FDI. Also, inflation, which is a proxy for macroeconomic stability, has been found to affect FDI significantly and the findings are in line with the study of Ahmad and Ahmed (2014). However, the findings contradict with the study of Gani and Al-Abri (2013). Gani and Al-Abri (2013) examined the impact of institutional stability and FDI in the Gulf Cooperation Council (GCC) countries and found a negative relationship between institutional stability and FDI. FDI, GNP and exports were seen to be endogenous variables. Again, this is consistent with the literature. In this study, GNP was used, although most studies used GDP. The GNP proxy was used because of a limitation in finding enough data for GDP. Concerning exports, previous studies have found it has a positive relationship with FDI and financial stability (Goswami, 2013). The positive correlation with FDI was more prominent for countries with manufactured exports. It implies that financial stability plays a more prominent causal effect on exports, in comparison to FDI.

Given the above findings and previous literature, FDI was chosen as among the endogenous variables, since the purpose of the study is to see institutional stability affects FDI. While vector error correction model can aid in identifying which variable is exogenous versus endogenous, it cannot provide the relative endogeneity and exogeneity of each variable. A more exogenous variable is explained by more the variability in its past. Identifying the relative exogeneity and endogeneity is necessary for policymakers as it allows them to implement effective policies using appropriate tools. Although results for orthogonalized VDC were obtained, the results were not analysed based on this. There are two critical limitations to this approach, which includes that the order of the variables is dependent on the VAR, and when one variable is shocked, the other variables are assumed to be switched off. These limitations do not exist for generalised VDC.

Table VI summarises the results of the generalised VDC. Institutional stability was found to be the most exogenous variable, which is consistent with expectations. The result is

\section{Foreign direct investment}

153

\begin{tabular}{lcccccccc}
\hline & HORIZON & LFDI (\%) & LGNP (\%) & LINF (\%) & LINST (\%) & LXP $(\%)$ & Total $(\%)$ & Rank \\
\hline LFDI & 3 & 61.01 & 2.62 & 1.97 & 16.95 & 17.44 & 100 & 3 \\
LGNP & 3 & 10.35 & 48.45 & 39.23 & 0.95 & 1.02 & 100 & 5 \\
LINF & 3 & 2.52 & 33.79 & 49.97 & 5.21 & 8.51 & 100 & 4 \\
LINST & 3 & 12.41 & 0.90 & 5.37 & 70.16 & 11.16 & 100 & 1 \\
LXP & 3 & 9.89 & 2.88 & 16.63 & 6.87 & 63.73 & 100 & 2
\end{tabular}

Source: Own elaboration

Table VI. generalised VDC 
JEFAS

24,47

in line with the study of Kurul (2017). The author finds that institutional quality affects FDI after reaching a certain level and significantly influences the FDI inflow of developing countries.

\section{Conclusion}

Several studies have been conducted on FDI and institutional development or other macroeconomic factors (Ahmad and Ahmed, 2014; Asif and Majid, 2017; Aziz, 2017). It is not surprising given that we operate in the highly integrated global community. This study focussed on the Canadian economy to see the role institutional stability that plays in its economy; given its economies have been the less volatile over the past decade as compared to other economies.

From the study, it can be concluded that there is an empirical causal link between FDI and institutional stability. Most of the literature found, both empirical and theoretical, do support this finding (Ahmad and Ahmed, 2014; Aziz, 2017; Kurul, 2017). Ahmad and Ahmed (2014) examined the impact of institutional quality on FDI for developing country by considering the case of Pakistan and found a significant influence of institutional quality on FDI. The findings also hold true for the case of developed country, for example, Canada. The studies of Aziz (2017) and Kurul (2017) also found a significant positive relationship between institutional quality and FDI. Thus, the key result of this study is that FDI and institutional stability are cointegrated in the long run. Also, institutional stability causes FDI since institutional stability is exogenous.

Canada is known to employ risk-averse policies in comparison to its neighbour, for instance, the USA. While Canada has been "looked down upon" for being so risk-averse, such policies have created a safer economic environment for institutions to flourish and remain stable over the long run. It is critical in attracting FDI since foreign investors want to feel that their investment is safe. Overall, Canadian policymakers are doing an excellent job of mitigating risk and creating a positive economic environment. They should continue to monitor and implement policies that encourage sound business practices and healthy levels of risk-taking. The global economy, however, is always changing, as such policymakers should be alert with regard to any changes in the environment.

\section{References}

Acemoglu, D., Johnson, S. and Robinson, J.A. (2005), "Institutions as a fundamental cause of long-run growth”, Handbook of Economic Growth, Vol. 1, pp. 385-472.

Ahmad, M.H. and Ahmed, Q.M. (2014), "Does the institutional quality matter to attract the foreign direct investment? An empirical investigation for Pakistan”, South Asia Economic Journal, Vol. 15 No. 1, pp. 55-70.

Appiah, M.O. (2018), "Investigating the multivariate granger causality between energy consumption, economic growth and $\mathrm{CO}_{2}$ emissions in Ghana”, Energy Policy, Vol. 112, pp. 198-208.

Asif, M. and Majid, A. (2017), "Institutional quality, natural resources and FDI: empirical evidence from Pakistan”, Eurasian Business Review, Vol. 8 No. 4, pp. 391-407.

Aziz, O.G. (2017), "Institutional Quality and FDI Inflows in A rab Economies, Finance Research Letters.

Bevan, A.A. and Estrin, S. (2004), "The determinants of foreign direct investment into european transition economies", Journal of Comparative Economics, Vol. 32 No. 4, pp. 775-787. 
Brunetti, A. and Weder, B. (1998), "Investment and institutional uncertainty: a comparative study of different uncertainty measures", Weltwirtschaftliches Archiv, Vol. 134 No. 3, pp. 513-533.

Buchanan, B.G., Le, Q.V. and Rishi, M. (2012), "Foreign direct investment and institutional quality: Some empirical evidence", International Review of Financial Analysis, Vol. 21, pp. 81-89.

Caporale, G.M. and Pittis, N. (1995), "Causality inference in bivariate and trivariate systems: some more results", London Business School Centre for Economic Forecasting.

Deaton, A. (1989), "Saving in developing countries: theory and review", The World Bank Economic Review, Vol. 3 No. suppl 1, pp. 61-96.

Demir, F. (2016), "Effects of FDI flows on institutional development: does it matter where the investors are from?”, World Development, Vol. 78, pp. 341-359.

Faundez, J. (2016), "Douglass north's theory of institutions: lessons for law and development", Hague Journal on the Rule of Law, Vol. 8 No. 2, pp. 373-419.

Freeland, C. (2010), "What Toronto Can Teach New York, NY and London”, Financial Times.

Gani, A. and Al-Abri, A.S. (2013), "Indicators of business environment, institutional quality and foreign direct investment in Gulf cooperation council (GCC) countries", International Review of Applied Economics, Vol. 27 No. 4, pp. 515-530.

Globerman, S. and Shapiro, D.M. (1999),. "The impact of government policies on foreign direct investment: the canadian experience", Journal of International Business Studies, Vol. 30 No. 3, pp. 513-532.

Goswami, N. (2013), "Determinants of trade development: panel evidence from South asia”, South Asia Economic Journal, Vol. 14 No. 1, pp. 17-33.

Hall, R.E. and Jones, C.I. (1999), "Why do some countries produce so much more output per worker than others” The Quarterly Journal of Economics, Vol. 114 No. 1, pp. 83-116.

Harms, P. and Ursprung, H.W. (2002), "Do civil and political repression really boost foreign direct investments?", Economic Inquiry, Vol. 40 No. 4, pp. 651-663.

Jun, K. and Singh, H. (1996), "The determinants of foreign direct investment: new empirical evidence", Transnational Corporations, Vol. 5 No. 3, pp. 67-105.

Kaufmann, D., Kraay, A. and Mastruzzi, M. (2011), "The worldwide governance indicators: methodology and analytical issues", Hague Journal on the Rule of Law, Vol. 3 No. 2, pp. 220-246.

Kurul, Z. (2017), "Nonlinear relationship between institutional factors and FDI flows: dynamic panel threshold analysis", International Review of Economics and Finance, Vol. 48, pp. 148-160.

Makki, S.S. and Somwaru, A. (2004), "Impact of foreign direct investment and trade on economic growth: evidence from developing countries", American Journal of Agricultural Economics, Vol. 86 No. 3, pp. 795-801.

Pesaran, M.H., Shin, Y. and Smith, R.J. (2001), "Bounds testing approaches to the analysis of level relationships", Journal of Applied Econometrics, Vol. 16 No. 3, pp. 289-326.

Rodrik, D., Subramanian, A. and Trebbi, F. (2004), "Institutions rule: the primacy of institutions over geography and integration in economic development", Journal of Economic Growth, Vol. 9 No. 2 , pp. 131-165.

Shakil, M.H., Mustapha, I.M., Tasnia, M. and Saiti, B. (2018), "Is gold a hedge or a safe haven? An application of ARDL approach", Journal of Economics, Finance and Administrative Science, Vol. 23 No. 44, pp. 60-76.

Stoian, C. and Filippaios, F. (2008), "Dunning's eclectic paradigm: a holistic, yet context specific framework for analysing the determinants of outward FDI: evidence from”, International Greek Investments, International Business Review, Vol. 17 No. 3, pp. 349-367.

\section{Foreign direct investment}

$+$ 
JEFAS

24,47

156
Tekin, R.B. (2012), "Economic growth, exports and foreign direct investment in least developed countries: a panel granger causality analysis”, Economic Modelling, Vol. 29 No. 3, pp. 868-878.

UNCTAD (2017), "World investment report 2017", in United Nations.

Wang, M.Y. and Meng, X. (2004), "Global-local initiatives in FDI: the experience of shenzhen, China", Asia Pacific Viewpoint, Vol. 45 No. 2, pp. 181-196.

Wheeler, D. and Mody, A. (1992), "International investment location decisions: the case", Of US Firms, Journal of International Economics, Vol. 33 Nos 1/2, pp. 57-76.

\section{Corresponding author}

Mohammad Hassan Shakil can be contacted at: mohammadhassanshakil@sd.taylors.edu.my

For instructions on how to order reprints of this article, please visit our website: 